\title{
CONTRIBUIÇÕES PARA A COLETA SELETIVA: ESTUDO DO DESCARTE DOS RESÍDUOS RECICLÁVEIS E NÃO RECICLÁVEIS
}

Monise Terra Cerezini ${ }^{1}$

Márcia Vilma Gonçalves de Moraes²

Resumo: O estudo foi realizado em uma escola de cursos técnicos profissionalizantes, onde circulam cerca de cinco mil pessoas por dia. O objetivo do estudo foi quantificar os resíduos recicláveis e não recicláveis gerados na unidade e verificar o seu correto descarte. Para isso, foram coletadas duas amostras das lixeiras da área externa do local de estudo. Foi constatado que a instituição deixa de enviar para reciclagem $39,6 \mathrm{~kg}$ de plástico e 4,8 $\mathrm{kg}$ de alumínio/média/mês, porém envia para cooperativa de reciclagem cerca de $155,5 \mathrm{~kg}$ de resíduos orgânicos/média/mês. Os usuários da instituição não praticam o correto descarte dos resíduos sendo necessário a implementação de um programa de Educação Ambiental para contribuir com o processo de sensibilização quanto ao correto descarte e separação dos resíduos na fonte.

Palavras-chave: Coleta Seletiva; Resíduos Recicláveis; Resíduos Não Recicláveis. 


\section{Introdução}

A coleta seletiva é definida pela Lei no 12.305, de 2 de agosto de 2010, que instituiu a Política Nacional de Resíduos Sólidos (PNRS), como a coleta de resíduos sólidos previamente segregados conforme sua constituição ou composição e abrange materiais recicláveis como papeis, plásticos, vidros, metais e embalagens longa vida (BRASIL, 2010). A coleta seletiva representa um importante instrumento da PNRS, juntamente com os sistemas de logística reversa e outras ferramentas relacionadas à implementação da responsabilidade compartilhada pelo ciclo de vida dos produtos (BRASIL, 2010).

No Brasil, a coleta seletiva está muitas vezes atrelada ao componente social, com a inclusão de catadores e o apoio de políticas públicas à organização de associações e cooperativas de materiais recicláveis. O Movimento Nacional dos Catadores, que representa a categoria de catadores de materiais recicláveis no país, possui cerca de 80 mil associados, sendo considerado o maior movimento de recicladores do mundo (PHILIPPO JR, et al., 2012).

Segundo dados do Instituto de Pesquisa Econômica Aplicada (IPEA), em 2017 o Brasil irá gerar em torno de 160 mil toneladas diárias de resíduos sólidos urbanos, sendo que cerca de $30 \%$ a $40 \%$ são considerados passíveis de reaproveitamento e reciclagem (SILVA, 2017). Porém, apenas 13\% do total de resíduos sólidos urbanos gerados no país é encaminhado para a reciclagem, sendo que este número poderia ser no mínimo seis vezes maior. Com isto mais de oito bilhões de reais são enterrados anualmente no Brasil, na forma de materiais recicláveis que poderiam ser recuperados, gerando trabalho e renda (SILVA, 2017).

A Resolução no 275, de 25 de abril de 2001, do Conselho Nacional do Meio Ambiente (CONAMA), estabeleceu o código de cores para os diferentes tipos de resíduos, a ser adotado na identificação de coletores de resíduos reciclaveis. Esta resolução padronizou as cores azul para recicláveis de papel/papelão; vermelho para recicláveis de plástico; verde para recicláveis de vidro; amarelo para recicláveis de metal; preto para resíduos de madeira; laranja para resíduos perigosos; branco para resíduos de serviços de saúde; roxo para resíduos radioativos; marrom para resíduos orgânicos e cinza para resíduo geral não reciclavel, misturado ou contaminado, não passível de separação (BRASIL, 2001).

Esta resolução também recomenda a adoção do código de cores para programas de coleta seletiva estabelecidos pela iniciativa privada, cooperativas, escolas, igrejas, organizações não-governamentais e demais entidades interessadas. Sendo assim, toda organização ou instituição que deseja realizar a separação dos resíduos recicláveis e não recicláveis deve seguir essa padronização de cores nos coletores, assim como informar os usuários sobre o correto descarte.

Diante do exposto, o presente artigo tem como objetivo quantificar os resíduos recicláveis e não recicláveis gerados em uma instituição de ensino, assim como verificar o correto descarte destes resíduos de acordo com a sua composição, buscando analisar a efetividade da implantação da coleta seletiva na área de estudo e o gerenciamento dos resíduos sólidos na fonte geradora.

Revbea, São Paulo, V. 13, № 4: 207-215, 2018. 


\section{Metodologia}

\section{Área de estudo}

O estudo foi realizado em uma instituição de ensino profissionalizante, localizada no município de Ribeirão Preto, estado de São Paulo. O local de estudo possui uma média de circulação de público de cinco mil pessoas por dia, com funcionamento de segunda a sexta, das 8:00 às 22:30 horas, com cursos profissionalizantes de nível técnico, cursos livres e curso de línguas, e aos sábados, das 8:00 às 17:00 horas, com cursos de pós-graduação latu sensu, cursos livres e cursos de línguas. A diversidade e faixa etária dos usuários é muito diversa, com estudantes com idade a partir de 10 anos nos cursos de línguas, e estudantes maiores de 21 anos nos cursos de pós-graduação.

A área de estudo possui 3 (três) pavimentos e 1 (um) subsolo. A área térrea é composta pela área de convivência dos alunos e demais usuários, sala de atendimento aos usuários, salas de aula, sala bar e cozinha gastronômica. 0 primeiro andar possui salas de aula, sala dos docentes, sala da administração, secretaria e salas da coordenação técnica e pedagógica. O segundo andar possui salas de aula e auditório e o subsolo é composto por 3 (três) laboratórios para os cursos de farmácia, enfermagem e rádio. Cada pavimento possui quatro banheiros, sendo dois femininos e dois masculinos.

O sistema de coleta seletiva foi implantado na instituição em 2014, com intuito de coletar os resíduos sólidos recicláveis e doá-los para a cooperativa de materiais recicláveis do município. Essa ação fez parte do programa de responsabilidade social e de ecoeficiência da instituição, com finalidades sociais, ambientais e econômicas.

\section{Coleta de dados}

Para o estudo foram selecionadas somente as lixeiras da área externa da instituição, presentes nos corredores dos três pavimentos e na área de convivência há grande circulação dos alunos e usuários. Não fez parte da amostra as lixeiras das áreas internas como administrativo, sala dos professores, secretaria, atendimento, salas de aula, laboratórios, banheiros e auditório.

Para a coleta dos dados, foram selecionados 10 (dez) conjuntos de lixeiras de resíduos recicláveis, sendo que cada conjunto é composto por 1 (uma) lixeira amarela, 1 (uma) lixeira verde, 1 (uma) lixeira azul e 1 (uma) lixeira vermelha. Também foram incluídas na amostra, 20 (vinte) lixeiras em alumínio, sendo 10 (dez) lixeiras com identificação de "resíduos não-recicláveis" e 10 (dez) com identificação de "resíduos recicláveis". Cada uma das lixeiras amostradas tem a capacidade de 30 litros. Para cada amostra do estudo foram coletados resíduos de 60 lixeiras. Portanto, a amostra total deste estudo foi de 120 lixeiras. O conjunto das lixeiras recicláveis com identificação das cores é mostrado na Figura 1 e o conjunto de lixeiras de alumínio na Figura 2. 


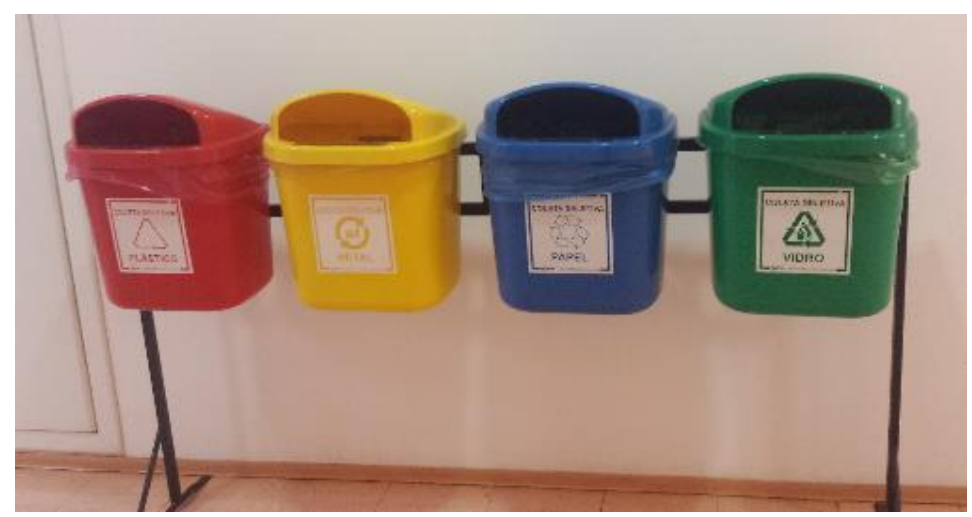

Figura 1: Conjunto de lixeiras recicláveis de acordo com a Resolução CONAMA oํ 275/2001.

Fonte: Autores (2018).

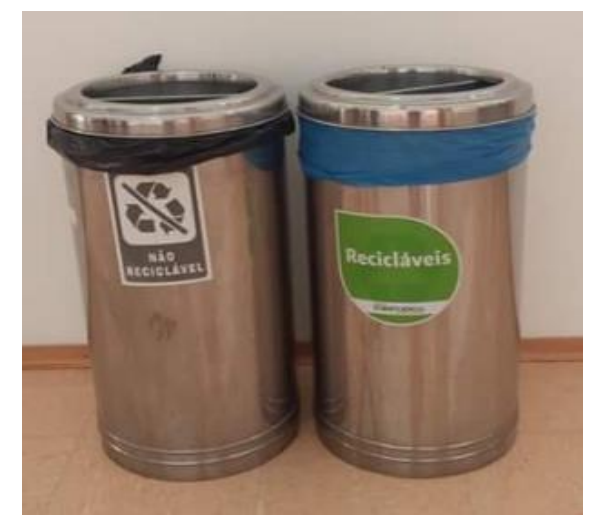

Figura 2: Conjunto de lixeiras de alumínio com identificação de "não recicláveis" e "recicláveis".

Fonte: Autores (2018).

As datas para a coleta das duas amostras dos resíduos contidos nas lixeiras foram definidas de acordo com a circulação de diferentes grupos de estudantes. A primeira amostra foi coletada em uma quarta-feira no período noturno, sendo predominante a circulação de estudantes de cursos técnicos. A segunda amostra foi coletada num sábado no período da tarde, sendo predominante a circulação de estudantes de cursos de pós-graduação.

Foi solicitado à gestora da área de limpeza que orientasse os demais funcionários da equipe sobre a não retirada dos resíduos das lixeiras amostradas em um período de 24 horas antes da realização da coleta. Durante a manipulação das amostras, os coletores dos resíduos utilizaram equipamentos de proteção individual (EPIs), como luvas de PVC, máscara descartável, avental descartável e sapatos fechados.

Os coletores foram divididos em seis grupos para coleta dos resíduos nas lixeiras amostradas, sendo o primeiro grupo responsável pela coleta das lixeiras amarelas, o segundo das lixeiras vermelhas, o terceiro das lixeiras azuis, o quarto das lixeiras verdes, o quinto das lixeiras com identificação de "resíduos não-recicláveis" e o sexto grupo das lixeiras com identificação de "resíduos recicláveis". Cada grupo de coletores ficou responsável pela coleta de 10 lixeiras, sendo um total de 60 lixeiras por amostra.

Revbea, São Paulo, V. 13, № 4: 207-215, 2018. 


\section{Análise de dados}

Os resíduos coletados foram colocados em sacos pretos de 100 litros e encaminhados para área de triagem, montada com uma lona de $30 \mathrm{~m}^{2}$. Foi utilizado uma balança antropométrica digital para pesagem dos resíduos, que foram pesados de acordo com o tipo de lixeira coletada. Foi utilizada uma caixa plástica padrão, tipo supermercado, com volume de 50 litros, para realizar a medição do volume dos resíduos. Para o cálculo do volume desta caixa foi utilizada a formula $(\mathrm{V}=\mathrm{A} \times \mathrm{B} \times \mathrm{C})$, sendo $\mathrm{A}=$ comprimento, $\mathrm{B}=$ largura $\mathrm{e} \mathrm{C}=$ altura. As medidas da caixa padrão utilizada no estudo foram as seguintes:

$A=56 \mathrm{~cm}, B=39 \mathrm{~cm}, C=23 \mathrm{~cm}$.

Aplicando a formula $\mathrm{V}=\mathrm{A} \times \mathrm{B} \times \mathrm{C}$, temos $\mathrm{V}=56 \times 39 \times 23$.

$\mathrm{V}=50.232 \mathrm{~m}^{3} \times 1.000 \mathrm{ml}=50$ litros.

\section{Resultados}

O total de resíduos encontrados são apresentados na Tabela 1, que representa os tipos de resíduos encontrados dentro das 10 (dez) lixeiras com identificação de "não reciclável" e na Tabela 2, que representa os tipos de resíduos encontrados dentro das 10 (dez) lixeiras com identificação de "reciclável" e dos dez conjuntos de lixeiras com as cores amarela, vermelha, azul e verde.

Tabela 1: Tipos de resíduos encontrados nas lixeiras de "não recicláveis".

\begin{tabular}{|c|c|c|c|c|c|}
\hline $\begin{array}{c}\text { Tipo de } \\
\text { resíduo }\end{array}$ & $\begin{array}{c}\text { Amostra 1 } \\
\mathbf{( K g )}\end{array}$ & $\begin{array}{c}\text { Amostra 2 } \\
\mathbf{( K g})\end{array}$ & $\begin{array}{c}\text { Média/dia } \\
\mathbf{( k g})\end{array}$ & $\begin{array}{c}\text { Media/mês } \\
\mathbf{( K g )}\end{array}$ & \% mês \\
\hline Plástico & 1,15 & 2,15 & 1,65 & 39,6 & 25,42 \\
\hline Alumínio & 0,20 & 0,20 & 0,20 & 4,8 & 3,08 \\
\hline Papel & 0,55 & - & 0,27 & 6,48 & 4,16 \\
\hline Vidro & - & - & - & - & - \\
\hline Orgânico & 2,85 & 5,9 & 4,37 & 104,88 & 67,33 \\
\hline Total & $\mathbf{4 , 7 5}$ & $\mathbf{8 , 2 5}$ & $\mathbf{6 , 4 9}$ & $\mathbf{1 5 5 , 7 6}$ & $\mathbf{9 9 , 9 9}$ \\
\hline
\end{tabular}

Tabela 2: Tipos de resíduos encontrados nas lixeiras de "recicláveis".

\begin{tabular}{|c|c|c|c|c|c|}
\hline $\begin{array}{c}\text { Tipo de } \\
\text { resíduo }\end{array}$ & $\begin{array}{c}\text { Amostra 1 } \\
\mathbf{( k g})\end{array}$ & $\begin{array}{c}\text { Amostra 2 } \\
\mathbf{( k g})\end{array}$ & $\begin{array}{c}\text { Media/dia } \\
\mathbf{( k g})\end{array}$ & $\begin{array}{c}\text { Media/mês } \\
\mathbf{( K g )}\end{array}$ & \% mês \\
\hline Plástico & 4,7 & 4,10 & 4,4 & 105,6 & 28,20 \\
\hline Alumínio & 1,25 & 1,01 & 1,13 & 27,12 & 7,24 \\
\hline Papel & 3,7 & 2,90 & 3,3 & 79,2 & 21,15 \\
\hline Vidro & 0,45 & 0,65 & 0,55 & 13,2 & 3,52 \\
\hline Orgânico & 2,95 & 9,5 & 6,22 & 149,28 & 39,87 \\
\hline Total & $\mathbf{1 3 , 0 5}$ & $\mathbf{1 8 , 1 6}$ & $\mathbf{1 5 , 6}$ & $\mathbf{3 7 4 , 4}$ & $\mathbf{9 9 , 9 8}$ \\
\hline
\end{tabular}

Para se obter o resultado da média por dia (media/dia/kg) foi feito a somatória do peso dos resíduos da amostra 1 e da amostra 2, dividido por dois. Para a média do mês (media/mês/kg) foi calculado o resultado da média por dia 
multiplicado por 24 dias, que representa a quantidade de dias que a unidade fica aberta, considerando 4 semanas por mês.

Os tipos de resíduos "não-recicláveis" encontrados nas lixeiras de resíduos recicláveis foram diversos. Em todas as lixeiras de recicláveis (verde, amarela, vermelha, azul e reciclável) foram encontrados guardanapos, touca descartável, restos de alimentos principalmente talos e cascas de frutas. $\mathrm{Na}$ lixeira verde (vidro) foram encontrados também restos de bolo, lâmpada fluorescente e cabelo (chumaço); na lixeira amarela (alumínio) foram encontrados bitucas de cigarro, lâminas de barbear e chiclete; na lixeira vermelha (plástico) foram encontrados embalagem plástica com restos de vaselina, além de bitucas de cigarro e luvas descartáveis; na lixeira azul (papel) foram encontrados embalagens tipo bandeja de isopor; e na lixeira de recicláveis ampolas plásticas de água para injeção e avental descartável.

Sabe-se que os resíduos orgânicos não devem ser misturados com os demais resíduos recicláveis para não prejudicar a reciclagem destes resíduos, sendo que os resíduos orgânicos podem ser transformados em adubos de forma segura em processos de compostagem ou enviados para coletas de resíduos urbanos para aterro sanitários.

A unidade deixa de enviar para cooperativa resíduos que deveriam ser reciclados como os recicláveis do tipo plástico uma média de $39,6 \mathrm{Kg}$ por mês sendo uma média em volume de uma caixa padrão por dia num total de 25 caixas por mês ou 1.250 litros. Quanto ao resíduo do tipo alumínio (latinhas) uma média de $4,8 \mathrm{Kg}$ por mês ou uma média em volume de meia caixa padrão por dia num total de 12 caixas por mês ou 600 litros. Em contrapartida a instituição envia para cooperativa resíduos não recicláveis em média um total de 155,5 kg por mês de resíduos orgânicos, sendo uma média em volume de uma caixa padrão por dia num total de 1.250 litros por mês de resíduos orgânicos alimentos.

Dados levantados em 2014 pela Associação Brasileira de Empresas de Limpeza Pública e Resíduos Especiais (ABRELPE), mostra que o Brasil reciclou $45,7 \%$ de papel, $58,9 \%$ de plástico do tipo PET e $20,9 \%$ do plástico (IRMP Índice de reciclagem mecânica do plástico). Segundo dados da Industria Brasileira de Arvore (IBA) no Brasil, em 2015 foram plantadas 7,8 milhões de hectares de arvores sendo que 34\% desta área e para uso no segmento da indústria de celulose papel. Os principais produtores mundiais de papel e os Estados Unidos com uma produção de 48milhoes de toneladas seguida da China com 17,9milhoes de toneladas o Brasil segue em quarto lugar com 17,4milhoes de toneladas sendo que $66 \%$ desta produção são destinadas a exportação (IBA, 2016).

A reciclagem anual de papeis e obtida pela divisão da taxa de recuperação de papeis pela quantidade total de papeis recicláveis consumidos no Brasil. As taxas de reciclagem dos papeis no mundo são a Coreia do Sul que recicla cerca de $91,6 \%$ seguida da Alemanha com $84,8 \%$, Japão com $79,3 \%$, Reino Unido com $78,7 \%$ e Espanha com73,8\%. O Brasil é o $12^{\circ}$ pais no ranking de reciclagem de papel com 45,7\% de papel reciclado em 2013 cerca de 
10,4milhoes de toneladas sendo que o $11^{\circ}$ neste ranking a Argentina com 45,8\% de papeis reciclados (ABRELPE, 2014).

Quanto a reciclagem do alumínio, o Brasil vem mantendo a liderança mundial de reciclagem de latas de alumínio tendo atingido, em 2014, o índice de 97,9\%, que corresponde a 260 mil toneladas de latas de alumínio recicladas seguida dos países Japão com 92,5\% a Argentina com 91,1\% seguida dos Estados Unidos com 67\%. Quanto a outros tipos de alumínio o Brasil recicla apenas 35,3\% (ABRELPE, 2014).

Os dados para reciclagem de plástico no Brasil são obtidos da indústria de reciclagem mecânica que converte os materiais plásticos descartados pôs consumo em grânulos passiveis de serem utilizados na produção de novos produtos plásticos. Dados levantados da ABRELPE - Associação Brasileira de Empresas de Limpeza Pública e Resíduos Especiais em 2014 o Brasil reciclou $58,9 \%$ do plástico tipo PET e 20,9\% do plástico IRMP (índice de reciclagem mecânica). A Figura 04 mostra o plástico IRMP em formato de grânulos.

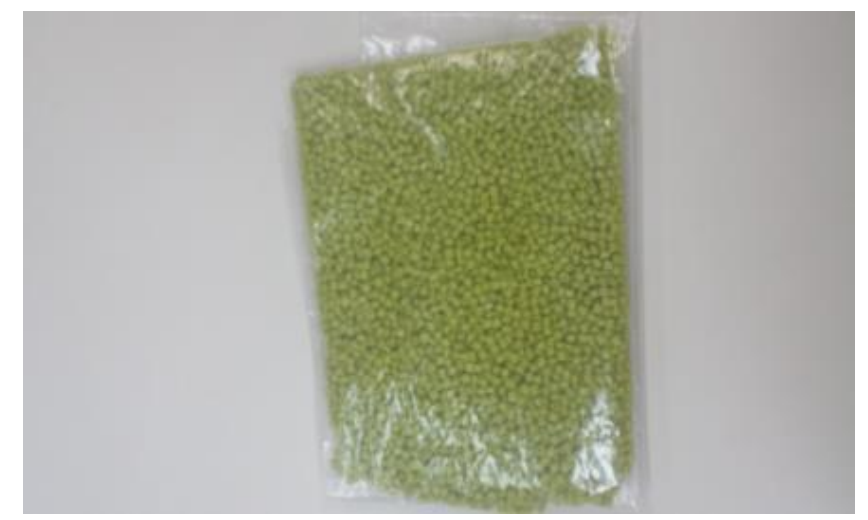

Figura 3: Grânulos plásticos processados na indústria de reciclagem mecânica.

Fonte: Autores (2018).

Os resíduos recicláveis coletados na instituição são doados para uma cooperativa de recicláveis, onde esses materiais são separados e vendidos a empresas de processamento. Esta cooperativa conta com 42 cooperados e também recebe resíduos recicláveis de outras empresas e de cerca de $1 \%$ da coleta seletiva da própria cidade. Os resíduos plásticos são prensados e vendidos para empresas que fazem o beneficiamento e o vidro é vendido para indústria de cerâmica da região. O papelão e as latinhas de alumínio são prensados e vendidos para empresas que comercializam estes resíduos.

Os resíduos de copos descartáveis e embalagens laminadas, pelo baixo valor agregado para comercialização, não são processados por essa cooperativa, sendo então enviados para outra empresa de beneficiamento de resíduos. Estes resíduos são gerados em grande quantidade, devido a presença de oito máquinas que comercializam esses produtos dentro da instituição.

A instituição implantou em abril de 2015 uma composteira e em setembro de 2016 um minhocario, com o intuito de reduzir os resíduos orgânicos descartados para o aterro sanitário e gerar composto orgânico. Porém os 
resíduos orgânicos utilizados neste processo são somente os resíduos gerados na cozinha industrial instalada para os cursos da área gastronômica da instituição e resíduos de jardim como folhas, restos de grama, galhos, não sendo encaminhado os resíduos orgânicos (restos alimentos) gerados pelos alunos e demais usuários da instituição. Por não receberem correta orientação sobre acondicionamento e descarte de restos de resíduos orgânicos, como cascas e talos de frutas, que foram os orgânicos mais encontrados nas amostras das lixeiras, o público não faz o descarte correto destes resíduos, que são descartados e levados ao aterro sanitário.

\section{Conclusão}

Pelos resultados encontrados neste estudo, foi possível notar que os usuários da instituição não estão sensibilizados quanto a importância da correta separação, descarte e acondicionamento dos resíduos na fonte geradora, visto que foram encontrados resíduos de diferentes categorias misturados. Atualmente, a instituição não conta com uma equipe ou um programa para orientação aos usuários (alunos e funcionários), quanto ao correto descarte dos resíduos, portanto é urgente e necessário a implementação de um programa de Educação Ambiental voltado para a coleta seletiva e importância do correto descarte e separação dos resíduos na fonte geradora.

A implantação da composteira, do minhocario e das lixeiras identificadas para a coleta seletiva na área de estudo, mostra que a instituição se preocupa com o gerenciamento dos resíduos sólidos que produz. Porém, além da implantação desses componentes, é necessário que os usuários sejam informados e sensibilizados para atuarem de forma eficiente no correto descarte e acondicionamento dos resíduos, participando ativamente deste processo. Os resíduos orgânicos gerados na instituição, poderiam ser corretamente separados e utilizados na composteira implantada na unidade, gerando composto orgânico. Atualmente esses resíduos são encaminhados para a cooperativa, misturados aos resíduos recicláveis, dificultando o processo de separação destes na cooperativa e sendo, posteriormente, encaminhados para o aterro sanitário.

Porém, mais do que apontar as falhas no gerenciamento dos resíduos sólidos, é importante compreender quais são dificuldades que os usuários estão enfrentando na hora de descartar os resíduos gerados e procurar soluções. Neste contexto, é preciso compreender se o problema está somente na falta de informação quanto à forma correta de realizar o descarte e a separação dos resíduos ou se o problema também está relacionado à estrutura da coleta seletiva, como localização, tamanho, identificação e disposição das lixeiras.

Essas dificuldades poderiam ser melhor compreendidas em entrevistas a serem realizadas com os usuários e em sala de aula durante as discussões sobre essa temática. Neste sentido, é preciso inserir o tema do gerenciamento dos resíduos sólidos no currículo dos diversos cursos existentes na instituição, abordando esta questão de forma interdisciplinar. Outra proposta é que a instituição envolva a cooperativa no gerenciamento dos resíduos recicláveis, solicitando que a mesma indique pontos a serem melhorados na separação dos

Revbea, São Paulo, V. 13, № 4: 207-215, 2018. 
resíduos. Também devem ser realizados, periodicamente, estudos gravimétricos dos resíduos sólidos gerados na instituição, como forma de monitorar as ações de melhoria, após a implantação do programa de Educação Ambiental.

Em estudo sobre a gravimetria de resíduos sólidos domiciliares e comerciais realizado na região próxima à área de estudo, Moraes e Cerezini (2017) concluíram que fica evidente a falta de informações quanto a forma correta de separação e descarte dos resíduos sólidos nos domicílios e comércios da comunidade local. Para superar este obstáculo, a instituição poderia, além da comunidade interna, também envolver a comunidade externa em ações de Educação Ambiental, visando prover informações quanto à correta separação dos resíduos sólidos gerados pela comunidade, funcionando como um ponto de disseminação de informações sobre a coleta seletiva.

Com essas ações, a instituição estaria prestando um serviço de formação e informação para toda sociedade, ressaltando a importância das escolas não apenas como agentes de formação profissional, mas também como pontos de fortalecimento da comunidade local, inserindo o ambiente como um instrumento pedagógico, conforme afirma Dias (1993) e utilizando a educação como um processo que possibilite construir mudanças necessárias no modo de agir dos usuários, construindo novos hábitos, valores e atitudes.

\section{Referências}

ABRELPE. Associação Brasileira de Empresas de Limpeza Pública e Resíduos Especiais. Panorama dos resíduos sólidos no Brasil. 2014. Disponível em: $<$ http://www.abrelpe.org.br/Panorama/panorama2014.pdf $>$. Acesso em 23/01/2017.

BRASIL. Lei no 12.305 de 2 de agosto de 2010. Institui a Política Nacional de Resíduos Sólidos. Brasília, 2010. Disponível em: <http://www.planalto. gov.br/ccivil 03/ ato20072010/2010/lei/12305.htm>. Acesso em 23/01/2017.

BRASIL. CONAMA. CONSELHO NACIONAL DO MEIO AMBIENTE. Resolução no 275 de 25 de abril de 2001. Disponível em: <http://www.mma.gov.br /port/conama/res/res01/res27501.html>. Acesso em 02/02/2017.

DIAS, G. F. Educação Ambiental: princípios e práticas. São Paulo: Gaia, 1993. IBA. Industria Brasileira de Árvores. Relatório IBA 2016. Disponível em: $<$ http://iba.org/images/shared/Biblioteca/lBA RelatorioAnual2016 .pdf>. Acesso em 24/01/2017.

MORAES, M. V. G.; CEREZINI, M. T. Índices comparativos de resíduos sólidos domiciliares e comerciais: análise gravimétrica realizada por alunos do curso de técnico em meio ambiente. Revista Educação Ambiental em Ação, n.59, 2017. PHILIPPO JR, A. et al. Política nacional, gestão e gerenciamento de resíduos Sólidos. Ed. Manole, Barueri: São Pulo, 2012.

SILVA, S. P. A organização coletiva de catadores de material reciclável no brasil: dilemas e potencialidades sob a ótica da economia solidária. Instituto de Pesquisa Econômica Aplicada. Ipea. 2017. Disponível em: <http://www.ipea. gov.br/portal/images/stories/PDFs/TDs/td 2268.pdf>. Acesso em 31/01/2017. 